\title{
Materialización y metapoética desde las novelas caballerescas a la épica colonial*
}

\author{
Materialization and Metapoetic Writing \\ from Chivalric Romance to Colonial Epic
}

STEPHANIE BÉREIZIAT-LANG

SFB 933 “Materiale Textkulturen”. Romanisches Seminar

RECIBIDO: 19 DE FEBRERO DE 2018 ACEPTADO: 24 DE AGOSTO DE 2018

Universität Heidelberg

Seminarstr. 3. Heidelberg, 69117. Deutschland

stephanie.lang@rose.uni-heidelberg.de

Orcid ID 0000-0001-5213-5175

Resumen: Esta contribución analiza rasgos comunes entre la novela caballeresca y la épica colonial en relación con la presencia de una marcada cultura material que, a su vez, remite a aspectos metapoéticos. Si la novela "orientalista" Tirant lo Blanc de Joanot Martorell (1490) y La Araucana de Alonso de Ercilla (1569-1597) comparten -así la hipótesisuna misma voluntad de autoafirmación y de apropiación de bienes y territorios, este "materialismo" va a la par con una exposición de la propia escritura dentro del mundo narrado. Paradójicamente, tal materialización de lo metapoético no conduce precisamente a la "materia": al asunto concreto de las conquistas. En Tirant, observamos una huida al mundo artificioso del simulacro, mientras que las aspiraciones violentas del héroe se esconden tras la noción de lo híperreal (Baudrillard). En La Araucana, el fetiche de la escritura disimula la violencia de la colonización. En cambio, los propios araucanos se oponen textualmente al fetichismo de la escritura, mediante una lógica de gasto (Bataille), alternativa a la acumulación de material y de escritura.

Palabras clave: Épica. Colonialismo. Novela caballeresca. Materialidad. Escritura.
Abstract: This contribution analyses analogies between the genres of chivalric romance and colonial epics, regarding the presence of a dominant material culture which is linked to metapoetical aspects. If the 'orientalist' romance Tirant lo Blanc by Joanot Martorell (1490) and Alonso de Ercilla's epic La Araucana (1569-1597) are supposed to share an aspiration for self-affirmation and for the appropriation of land and goods, this 'materialism' goes along with the exposition of writing itself within the narrated world. Paradoxically, this concretion or materialization of the metapoetic does not lead to the 'materia', the concrete matter of the conquests. In Tirant, the text escapes to an artificial world of simulacrum, and the notion of hyper-reality (Baudrillard) hides the hero's violent aspirations. In La Araucana, the fetish of writing dissimulates the violence of colonization. However, the araucans textually oppose to the fetishism of writing -by defending a logics of expense (Bataille) as an alternative to the accumulation of material and of writing.

Keywords: Epic. Colonialism. Chivalric Romance. Materiality. Writing.

\footnotetext{
* Este artículo ha sido realizado en el marco del proyecto Materiale Textkulturen, SFB 933 de la Universidad de Heidelberg.
} 
DE LA MATERIA CABALLERESCA AL DESEO COLONIAL

- n el Amadís de Gaula de Garci Rodríguez de Montalvo, la Ínsola Firme es el mágico lugar en el cual los caballeros pueden poner a prueba su mérito caballeresco tanto en las armas como en cuanto al verdadero amor. En esta isla encantada, no solo les espera la consolidación de su honra, sino también un paisaje de maravillosas riquezas, repleto de mármol, cristal y piedras preciosas. Al hacerse señor de la isla, Amadís la elogia:

-Allí nos farán honra, demás del plazer que ternemos, porque aquella tierra es muy viciosa, abundada de todas las cosas y de [...] fermosas mugeres [...] y yo en ella tengo muchas y preciadas joyas de gran valor que para nuestras necesidades serán bastantes. (I, 569)

El mérito de los caballeros -así sugiere la cita- requiere su justa equivalencia en materia preciosa, transformando el valor del caballero en valor material. El aspecto libidinoso de esta lógica aparece muy claramente en la evocación de las "fermosas mugeres", también ellas de "gran valor". $\mathrm{Al}$ crear mundos repletos de materia preciosa, se permite visualizar y hacer tangible el prestigio del mundo caballeresco, aunque al mismo tiempo lo quite del alcance de la mano del lector, creando en él un deseo insaciable por estas maravillas. Si en estos espacios se condensa la 'materia' caballeresca en abundancia material, no solo se pone a prueba al héroe (y con él al lector) frente a los códigos sociales, sino que también se pone en perspectiva el texto literario frente a las exigencias de su sistema textual. Esta materialización ${ }^{2}$ de aspectos metapoéticos es una constante tanto en las narrativas de caballerías como en novelas caballerescas supuestamente más realistas, ${ }^{3}$ y se actualiza, con los espacios artificiales de índole petrarquista, también en la lírica y, sobre todo, en la épica renacentista. En esta contribución se analizará precisamente esta continuidad en cuanto a una materialización de lo metapoético, a partir de dos textos a primera vista muy diferentes: la novela valenciana Tirant lo Blanc de Joanot Martorell, ${ }^{4}$

1. Según el modelo del Pays de Cocagne, la Ínsola Firme ofrece, como un parque temático, un mecanismo de compensación que disimula las estructuras económicas y de poder. Ver Harney.

2. Por materialización se entiende aquí la estrategia narrativa de hacer tangibles los aspectos metatextuales y metapoéticos dentro del mundo narrado, vinculándolos a la presencia material de objetos preciosos.

3. Desde esta perspectiva es irrelevante la antigua distinción entre novela caballeresca y de caballerías. Algunos críticos han querido ver en Tirant lo Blanc rasgos de un realismo moderno; ver Vargas Llosa 10; Beltrán 152-75.

4. Las citas de la edición de Martí de Riquer (1983) vienen con la sigla TB, seguida de volumen y página. 
impresa en 1490, y la épica colonial La araucana de Alonso de Ercilla, ${ }^{5}$ publicada entre 1569 y 1597. Estos textos no solo difieren de género literario e idioma, sino que también afectan terrenos históricos y geográficos muy diferentes. Mientras que Tirant lo Blanc trata las aventuras de un caballero bretón entre el Mediterráneo, África del norte y Constantinopla, La araucana tiene lugar en Chile, en el contexto de la expansión imperial hacia el Nuevo Mundo. En cambio, sí se puede observar cierta permeabilidad de los géneros literarios en cuanto a tópicos, procedimientos textuales y sistemas ideológicos. ${ }^{6} \mathrm{Ya}$ en la Poética de López Pinciano, Fadrique equipara poemas épicos y romances de caballerías:

[L]os amores de Teágenes y Cariclea, de Heliodoro, y los de Leucipo y Clitofonte de Achiles Tacio, son tan épica como la Ilíada y la Eneida; y todos esos libros de caballerías, cual los cuatro dichos poemas, no tienen [...] diferencia esencial que los distinga. (165)

De hecho, en el 1500 el género caballeresco se acerca a las propuestas encomiásticas de la épica (Gagliardi 252-57). Frente a la reticencia general hacia las 'historias fingidas' y las traducciones o descubrimientos de manuscritos fingidos -tópicos que también se retoman en el Amadís o el Tirant-, se busca elevar el género hacia el de los specula principis y establecer vínculos entre el héroe ejemplar y sus hazañas -aunque ficticias- y la realidad contemporánea del imperio español. De este modo, los relatos caballerescos se acercan al proyecto épico de "fortalece[r] la legitimidad dinástica" y el "ennoblecimiento de las armas" (Vega 135). ${ }^{7}$ Viceversa, la épica renacentista incorpora elementos maravillosos a la descripción de sucesos históricos, debido, como sugiere Caravaggi, a una percepción de la 'realidad' histórica contemporánea que, con las conquistas asombrosas traspasa las fronteras de lo 'verosímil' (211-15). Insertándose ambos en un mundo ficcional que mal disimula sus alusiones a una realidad histórica vivida y juzgada por los contemporáneos, la épica como un género para los veteranos de las guerras coloniales (Vega 115) y las narrativas caballerescas pueden compartir cierta dimensión ideológica y pragmática textual. ${ }^{8}$

5. Se cita de la edición de Isaías Lerner (2009), con las siglas AR, seguida de la página.

6. Para la "permeabilidad" de los géneros, ver Gagliardi, Rössner y Prampolini.

7. Para la "voluntad de enaltecer y difundir" la ideología imperial de Carlos v en las novelas de caballerías, ver Gagliardi 265.

8. Vilà considera el "virgilianismo político" de los intelectuales castellanos del siglo XVI como un aspecto fundamental para constituir la épica como "memoria del presente" (1). 
Tanto en Tirant lo Blanc como en La Araucana la movilidad conquistadora hace confluir militia Christi y apropiación de riquezas y territorios. Un primer factor para acercar ambos textos se encuentra en la figura del Imperio otomano. Se ha descrito la "orientalización" del paradigma caballeresco artúrico (ver Wild) simultáneamente como una continuación del paradigma de la Reconquista y como prefiguración de la empresa colonial americana. La ficticia conquista de Constantinopla por el héroe Tirant, imaginada precisamente en los decenios después de la real caída de Constantinopla frente al Imperio otomano en 1453, sería, en palabras de Wild, un "mecanismo de compensación" que traslada la conquista hacia una "conquista textual" inscrita en un espacio perdido (236). . Es tanto más significativo que en La araucana, en medio de las descripciones de la conquista colonial chilena, la famosa escena con el mago Fitón establezca un vínculo con este mismo trauma de la supremacía europea, y relate, desde la visión en una bola de cristal mágica, la batalla de Lepanto de $1571 .^{10}$ La victoria de la liga católica contra los otomanes, observada desde América, repite el acto solemne con el cual Tirant obtiene la victoria para los españoles. De este modo, tal y como en el viaje a Oriente que realiza Tirant, se confiere ahora un toque de militia Christi a la conquista imperial. ${ }^{11}$ El enfático deseo de "somet[er] hoy aquí todo el Oriente" (AR 665) de Lepanto actualiza la "justísima causa" (AR 666) de la reconquista de la Tierra Santa y la traslada a la causa colonial (ver Galperin). Así, mediante la modelación ficcional de nuevas Reconquistas de Oriente y la compensación literaria de sucesos históricos, la novela caballeresca Tirant lo Blanc de finales del siglo $\mathrm{XV}$ y la épica de casi una centuria después comparten una misma preocupación encomiástica. En cuanto a la dimensión cristológica, Tirant y La Araucana solo se diferencian en la repartición de los roles: si al final del periplo de Tirant, este aparece como un mesías (Penzkofer 104), en el texto de Ercilla las configuraciones crísticas no se encuentran del lado de los conquistadores, sino más

9. Wild ve las reconquistas imaginarias de territorios efectivamente perdidos como momentos de compensación en el sentido freudiano. La "symbolhafte Rückeroberung durch Schrift" (236) constituye una "imaginäre Makrotopographie, die textuell behauptet, was militärisch verloren ist" (243). También alude a la translación del paradigma a la épica colonial como "Überschreibung" a través de una exportación del paradigma antiosmánico hacia el Nuevo Mundo (24647). Para la noción de translatio como transactio económica, ver Folger.

10. Para la interpretación de este episodio como "Ermöglichungsstrategie für die Darstellung von historischen Ereignissen", ver Friedlein 198-306.

11. La tendencia de cristianizar la Eneida en la épica renacentista se observa desde Tasso, y extiende la noción de reconquista territorial al terreno moral, ver Caravaggi 209. 
bien de los indios (Davis 47). En ambos casos, en cambio, la noción de conquista tiene que verse en el ámbito de una expansión del cristianismo ${ }^{12} \mathrm{y}-\mathrm{a}$ nivel textual- de una recuperación discursiva del Santo Grial, en forma de nuevas 'questes' artúricas.

He aquí un segundo factor que permite vincular los dos textos; a saber, su situación epistémica en una modernidad temprana en la cual los valores caballerescos se encuentran en desuso. En el Tirant se ha observado un paso de los modelos artúricos, ya señalados como anacrónicos, hacia una nueva actitud de un "scepticism, the positivism and the man-centred outlook of a new age" (Yates 182). ${ }^{13}$ De manera similar, en La Araucana se ha visto una concurrencia entre "traditional discourse practices [as] a powerful residual ideology" y "a decidedly modern and unaristocratic activity: financial speculation" (Davis 59). En cuanto a la tesis de este artículo, se podría decir que la material culture presente en estos textos va a la par con la lógica interna de este nuevo "materialismo". Despidiéndose de los valores abstractos de la caballería, estos textos trasladan la 'materialización' a unos episodios aislados que exponen, encuadran o archivan el mundo maravilloso de la caballería. Sintomáticamente, estos espacios propiamente ficcionales se revelan como los lugares de la propia escritura.

En lo que sigue se cuestionará esta hipertrofia de materia tanto en la novela caballeresca como en la épica colonial. ¿A qué se debe esta necesidad de crear mundos materiales llenos de objetos preciosos? En los dos textos aquí tratados, estos pasajes materializan también la propia escritura: como lugares metapoéticos condensan y exponen las referencias textuales, creando un mundo del simulacro. ${ }^{14}$ En un segundo momento, se demostrará que La Araucana, con su perspectiva doble entre la propia escritura como metadiscurso y el mundo araucano (no-escritural), modela, al mismo tiempo, una lógica alternativa a esta acumulación de materia y de escritura: la lógica del don y del gasto.

12. En La Araucana se observan la estilización de los conquistadores como mártires y los "paganos" como "verdugos de los mártires cristianos" (AR 687) y el gesto repetido de erigir la cruz tras la victoria (AR 690), ver Galperin.

13. Para Tirant lo Blanc como documento de un cambio epistémico, ver también Badia.

14. Como se detallará en el siguiente apartado, la noción de simulacro se entiende aquí en el sentido de Jean Baudrillard. Aunque, en principio, este aporte teórico concierne a otro ámbito histórico y cultural, constituye una herramienta conceptual que permite acercarse desde otra perspectiva a la dimensión tanto ideológica como estética de los textos literarios. Además, se intenta así desligar algunos aspectos teóricos 'posmodernos' de su contexto histórico inmediato y (re-) historizar su terminología. 
TIRANT LO BLANC: FETICHE CONQUISTADOR E HIPERREALIDAD

En el texto de Joanot Martorell, la conquista del Imperio de Occidente y la aspiración al poder supremo se ilustran de manera lúdica a través de la conquista amorosa de la princesa Carmesina. ${ }^{15}$ Ya en el mismo cuerpo de Carmesina se encarna así la noción abstracta de conquista. Esta figura se materializa aún más y se deshumaniza al desdoblar y proyectarla sobre los espacios opulentos del mundo narrado.

El primer encuentro del caballero Tirant con Carmesina tiene lugar en el palacio ricamente ornado del emperador de Constantinopla. Tal y como Amadís encuentra en la Ínsola Firme la confirmación de su valor caballeresco, es en este espacio opulento donde Tirant puede poner a prueba su valor. El primer paso constituye la conquista de su objeto de deseo inmediato, la princesa Carmesina. Quiero examinar dos escenas clave: en la primera, Tirant encuentra por primera vez a la princesa Carmesina, y en la segunda, ostenta su afán conquistador y consume (al menos metafóricamente) su victoria erótica. Veamos el primer encuentro:

[P]er la gran calor que feia, [Carmesina] estava mig descordada mostrant en los pits dues pomes de paradís que crestallines parien, les quals donaren entrada als ull de Tirant, que d'allí avant no trobaren la porta per on eixir [...]. L'Emperador pres per la mà a sa filla Carmesina [...] e entraren en una altra cambra molt ben emparamentada e tota a l'entorn hestoriada de les següents amors: de Floris e de Blanxesflors, de Tisbe e de Píramus, d'Eneas e de Dido, de Tristany e d'Isolda, e de la reina Ginebra e de Lançalot, e de molts altres, que totes llurs amors de molt subtil e artificial pintura eren divisades. E Tirant dix a Ricard:

-No creguera jamés que en aquesta terra hagués tantes coses admirables com veig.

E deia-ho més per la gran bellea de la Infanta. Emperò aquell no ho entès. (TB, I 222)

Resalta la comparación de la "cárcel de amor" que devora los ojos de Tirant para guardarlos prisioneros en un bortus conclusus paradisíaco, cuyas manzanas remiten al fruto del amor, pero también, claro está, a la seducción engañosa y al pecado. Analógicamente al ingreso en este paraíso sin salida, el paso a la se-

15. Para la superposición del discurso cortés y del bélico, y el camuflaje discursivo de la aspiración al poder, ver Béreiziat-Lang. 
gunda cámara abre la vista hacia un nuevo escenario, un hortus conclusus de la ficción literaria. Con Tristán y Lanzarote la filiación artúrica es muy explícita, pero también aparecen ecos de la épica clásica. Según Vargas Llosa, estos "símbolos premonitorios" inscriben la pareja Tirant-Carmesina en la línea genealógica de un "mundo eterno del mito" (47). En cambio, me parece que, en vez de 'simbolizar' algo y cargar la pareja Tirant-Carmesina con atributos semánticos, este espacio disfrazado de paramentos y repleto de la "molt subtil e artificial pintura" remite al mismo artificio del texto, borrando los límites entre realidad y simulación.

Goldberg ve en estos entornos "more brightly colored than the real world" (380) los signos de una "new unreality", pero me parece más adecuado captar esta "unreality" con la noción de lo híperreal según Jean Baudrillard. En este mundo artificial medialmente construido, los signos e imágenes circulan libremente y remiten, ya no a una realidad, sino a su propia estructura de simulación, la "hyper-réalité du code" (Baudrillard 1976, 8). Al mismo tiempo, con esta pérdida de referencialidad se esconde el vínculo entre la simulación y la 'realidad' de los sistemas de producción de estos signos: lo híperreal es "une machine de dissuasion mise en scène pour régénérer en contre-champ la fiction du réél” (1981, 26). Así, la híperrealidad simulada esconde las deficiencias de esa misma 'realidad' que encubre -acercándose, de este modo, a la noción del fetiche- ${ }^{16} \mathrm{El}$ mecanismo subyacente que el fetiche baudrillardiano esconde -vinculando el aspecto económico de Marx a la categoría de deseo freudiana- es otra vez el mismo sistema de simulación, el perverso deseo del código:

Quelque chose comme un désir, comme un désir pervers, le désir du code, se fait jour ici, un désir qui vise la systématicité des signes [...]. Dans ce sens, le fétichisme n'est pas la sacralisation de tel ou tel objet, de telle ou telle valeur [...], c'est celui du système en tant que tel. (Baudrillard 1972, 101)

No es casualidad que, etimológicamente, la noción de 'fetiche' se haya vinculado a la emergencia del comercio 'moderno' y al ámbito transcultural colonial de los mercaderes portugueses en África (Baudrillard 1972, 99; Pietz 17). Se podría pues ver, en la puesta en escena de estos recintos híperreales, la emergencia de una episteme posmedieval que va a la par con la valoración del propio sistema del intercambio de signos (y bienes). Como estructura de superfi-

16. Para las analogías conceptuales entre "fetiche" y "simulacro" según Baudrillard, ver Blättler. 
cie que encubre un mecanismo subyacente, el fetichismo esconde la contraparte violenta de la imposición conquistadora. Es significativo que Baudrillard, aunque se refiera sobre todo al mundo 'posmoderno', al imponer una dimensión histórica del simulacro en tres "ordres" (1976, 77), traza el Renacimiento como primera etapa de un proceso que elimina sucesivamente la diferenciación entre lo 'real' y su representación: "C'est donc dans le simulacre d'une «nature» que le signe moderne trouve sa valeur" (79). Desde esta visión histórica, tanto Tirant lo Blanc como, aún más, la temprana épica colonial pueden considerarse como manifestaciones textuales de estas primicias del simulacro moderno que se materializan en objetos fetiches dentro del mundo ficcional. En esta lógica, los objetos son fetiches, ya no en tanto que sacralizan un determinado objeto material, sino porque sacralizan, detrás de la materialización, el mismo sistema, el código literario de la imitación discursiva, como un sistema de negociación de prestigio ${ }^{17}$ y de creación textual. El material simula el prestigio de una continuidad discursiva, y remite al mismo artificio del texto.

En esta escena del Tirant, la ficción literaria se antepone como una pared a los sucesos contados. El espacio disfrazado de paramentos ya no simboliza nada en concreto, y no remite a otra cosa que a la propia figura de simulación. $\mathrm{Al}$ mismo tiempo que se materializan en las paredes, Tirant y Carmesina se virtualizan, llegan a ser meras copias vacías dentro de su sistema de referencias, que es el de la imitación discursiva. Es sintomático el error de interpretación del personaje Ricard (en el párrafo citado arriba), quien cree que Tirant habla de la belleza de las parejas pintadas, mientras que este se refiere a lo que tienen realmente ante sus ojos: la princesa Carmesina. No es más real ella que Isolde, ni Tirant que Tristán, tampoco dentro de la lógica intradiegética. Todas las parejas figuran como copias equivalentes, en una serie de meros significantes sin referencia. Los decoros preciosos y la materialización pictórica reduplican las acciones de los protagonistas y, en último término, las sustituyen dentro de la cadena de réplicas, sin distinguir entre la trama actual, los modelos literarios y la figura de simulación discursiva.

La simulación fetichista materializada en el ornato del edificio se concreta aún más en la siguiente escena, que ilustra la conquista erótica de la prin-

17. En su artículo sobre Os Lusíadas de Camões, Folger vincula la idea del fetiche a la "subjetividad interpasiva”, según Slavoj Žižek. Si Folger muestra cómo el texto mismo se vuelve un objeto de intercambio en una red de intereses materialistas dentro del sistema colonial de circulación de bienes, este artículo averigua cómo la materialización se condensa en la puesta en escena de los mismos objetos intradiegéticos. 
cesa por Tirant (cap. 189). Tirant consigue entrar en la habitación de Carmesina y durante sus juegos amorosos y charlas, ella le regala su peine. A los intentos de Tirant de ir más allá y tocarla, Carmesina se rebela, así que este solo consigue estirar la pierna y tocarla con el zapato debajo de la falda. Y la narración sigue así:

Com Tirant fon en sa posada, descalçà’s les calces e sabates; e aquella calça e sabata ab què havia tocat a la Princesa davall les faldes, féu-la molt ricament brodar; e fon estimat lo que hi posà, ço és, perles, robins e diamants, passats vint-e-cinc-mília ducats.

E lo dia del reng se calçà la calça e la sabata; e tots quants hi havia [...], estaven admirats de la gran singularitat de les pedres fines que hi havia, ne tan rica sabata de cuiro no era estada vista. E en aquella cama no portava arnès negú, sinó en la sinestra; e paria estar molt bé. Per cimera portava damunt l'elmet quatre pilars d'or, lo Sant Greal fet a manera d'aquell que Galeàs, lo bon cavaller, conquistà; sobre lo Sant Greal estava la pinta que la Princesa li havia dada, ab un mot que hi havia, e qui llegir-ho sabia deia: No ha virtut que en ella no sia. E així ixqué aquell dia. (TB, I 410)

$\mathrm{Al}$ igual que algunas imágenes de la escena anterior, el Santo Grial y el peine, como objeto de deseo, remiten a la tradición épica artúrica. En Le Chevalier de la charette de Chrétien de Troyes, Lancelot encuentra un hermoso peine de marfil, con algunos cabellos dorados de la reina Ginebra en él, lo que le lleva a adorar el peine en sustitución de su dama (Beltrán 152). Este fetichismo del objeto y su connotación libidinosa sigue en el Tirant. En la construcción artificiosa de la cimera, es clara la alusión sexual entre el peine fálico y el cáliz receptor. En cambio, la virtud que se supone encontrar en ella es muy discutible. El rasgo simulador del fetiche consiste en el hecho de que se atribuye un valor a un objeto que intrínsecamente no le corresponde y que, al mismo tiempo, cubre una deficiencia latente. En la cita resalta la riqueza del ornato de oro y piedras preciosas, cuyo precio exacto curiosamente se indica. $\mathrm{Al}$ mismo tiempo, está claro que esta puesta en escena solo apunta hacia la apariencia ("paria estar molt bé" / "tots [...] estaven admirats"). Cubriendo el simple zapato con una materialidad exuberante, se intenta resaltarle un valor simulado y compensar, a la superficie, la deficiencia de valor del propio cuerpo del héroe, que debajo se esconde. Así, se intenta compensar la deficiencia de la acción del caballero y parodiar el sistema de valoración de la caballería. A la vez, se parodia la imitación literaria: ahora, la 'queste' artúrica da solo lugar a una simula- 
ción superficial de virtudes. El Santo Grial como trofeo elevado a un pedestal dorado viene a ser una figura vacía sin referencia fuera del mundo de la ficción literaria. Según Lacan, el Grial es el fetiche por excelencia: corresponde al significante puro, al puro receptáculo, en el cual lo realmente adorado -la sangre de Cristo- falta: "[...] le sang du Graal est précisément ce qui, dans le Graal, manque" (170). ${ }^{18}$ También en el ornato de Tirant, que cubre y esconde la deficiencia de sus hechos, la 'sangre' está ausente detrás de la puesta en escena opulenta. Mediante la ostentación fetichista del Grial en su disfraz caballeresco, tanto la intrusión violenta hacia el cuerpo de Carmesina como la penetración violenta en el Imperio de Constantinopla se disimulan, y su falta de 'valor' se compensa ricamente con el valor vacío de los objetos. Al mismo tiempo, el Grial como objeto sin valor intrínseco es la figura fetiche de la imitación literaria discursiva, en la cual el mismo Tirant no llega a distinguirse; y esto a pesar de la originalidad de su ornato y de la "gran singularitat" de su performance. Como materia prima, el imaginario artúrico se remodela en una quête caballeresca materializada que es pura figura de simulación. ${ }^{19}$ Lo que debajo de la ostentación se encubre, es la violencia (colonial) de la conquista de oriente, la toma de poder y la autosacralización del héroe ilegítimo, ${ }^{20}$ mediante sus trofeos fetiches.

\section{LA ARAUCANA: 'MATERIA' ÉPICA Y MATERIALIZACIÓN METAPOÉTICA}

También en La Araucana se puede observar una materialización de la escritura. Esta cristalización metapoética puede asimismo dar indicios sobre la orientación ideológica del texto. El extenso poema épico de Alonso de Ercilla sobre la conquista de Chile ha suscitado críticas bastante divergentes en cuanto a su trasfondo ideológico. Esta ambigüedad que oscila entre la apología del imperialismo hispánico, ${ }^{21}$ y la creación de un héroe indígena colectivo ${ }^{22}$ es quizás el primer mérito literario de este texto.

18. Según Lacan, el Vacío designa el lugar de la "Chose": "Cette Chose sera toujours en quelque sorte représentée par un vide, précisément en ceci qu'elle ne peut [...] qu'être représentée par autre chose. Mais dans toute forme de sublimation le vide sera déterminatif" (155).

19. Respecto al torneo cortesano, Cátedra habla de un "paso de la competición al simulacro, del agon a la mimesis" (75).

20. Para la ilegitimidad del héroe y la cuestión libidinal, ver Béreiziat-Lang.

21. La inserción de las "guerras justas" europeas en la trama chilena compensa la dimensión antiheroica de la guerra colonial, ver Quint; Davis; Lagos.

22. Galperin ve una deconstrucción total de la ideología imperial. Según Pastor, La Araucana es un primer reflejo de la "emergencia de una conciencia hispanoamericana" (349). 
Como testigo de la guerra de Arauco, ${ }^{23}$ Alonso de Ercilla-personaje asiste a una "aventura" similar a la de Tirant, la conquista del territorio de los Otros, solo que estos ya no son musulmanes o africanos sino araucanos. Al igual que en el Tirant, en esta conquista se cuestionan y actualizan los valores caballeres$\cos ,{ }^{24}$ como paradigma literario y también como canon de valores. Como ha observado Rössner, América se ofrece como "exilio para los valores caballerescos" (194).

Como en el Tirant, la conquista se desarrolla en un entorno en el cual se entretejen referencias textuales, procedentes de una tradición épica grecorromana y europea. Y de nuevo, en estas escenas metaficcionales, la materia literaria se reifica en unos objetos de exuberante valor material que condensan un deseo. El oro como material explícitamente vinculado al comercio colonial y extraído de las tierras americanas (AR 136) viene a ser la objetivación para una búsqueda "material" también en el sentido de la materia poética.

La inscripción poética en los mismos territorios del Nuevo Mundo se cumple en la última y póstuma parte de La araucana. En estos capítulos, donde el valor autopoético del poema se intensifica (Friedlein 306), Don Alonso participa en una expedición hacia la tierra incógnita del sur de Chile, e inscribe en un árbol un poema como "marca" colonizadora:

Pero yo por cumplir el apetito

Que era poner el pie más adelante

fingiendo que marcaba aquel distrito, cosa al descubridor siempre importante, corrí una media milla do un escrito quise dejar para señal bastante, y en el tronco que vi de más grandeza escribí con un cuchillo en la corteza:

Aquí llegó, donde otro no ba llegado, don Alonso de Ercilla, que el primero de un pequeño barco deslastrado, con solos diez pasó el desaguadero el año de cincuenta y ocho entrado

23. Se ha resaltado el aspecto autorreferencial de muchos pasajes (Friedlein 281-86). El pretendido testimonio personal se reivindica por el narrador desde el prólogo.

24. Ver Pastor; Quint ve en los episodios amorosos de La Araucana rasgos caballerescos como parte de una queste específicamente literaria. 
sobre mil y quinientos, por hebrero,
a las dos de la tarde, el postrer día,
volviendo a la dejada compañía. (AR 944-45)

No por azar escoge el árbol "de más grandeza”, y no por azar lo marca con un cuchillo. ${ }^{25} \mathrm{El}$ afán de gloria es acompañado por un gesto violento, dejando una cicatriz en la naturaleza, la cicatriz de su 'descubrimiento' entendido como apropiación. También la historización del espacio con la marca de la fecha se puede considerar una inserción a la lógica cristiana del colonizador. ${ }^{26} \mathrm{La}$ metatextualidad opera aquí como apropiación textual y literal de un espacio imaginario, mediante la inscripción/ incisión de sus superficies.

Frente a esta escena, que abiertamente vincula la actitud colonial al acto de escribir, es significativo que la escritura -sobre todo cuando da entrada a la temática amorosa desde la segunda parte del texto- ${ }^{27}$ huye de los entornos americanos y se refugia, de nuevo, en una híperrealidad artificial. En el mágico entorno de Fitón, don Alonso se ve confrontado a sus modelos ficcionales en los muros de un edificio ricamente ornado, tal y como Tirant en las paredes cubiertas de paramentos en el palacio oriental:

Salimos a un hermoso verde prado, que recreaba el ánimo y la vista, do estaba en ancho cuadro fabricado un muro de belleza nunca vista, de vario jaspe y pórfido escacado $y$ al fin de cada escaque una amatista; en las puertas de cedro barreadas mil sabrosas historias entalladas.

Abriéronse en llegando el mago a punto y en un jardín entramos espacioso,

25. Al considerar la última expedición al sur chileno como "pacífica", Lagos pasa por alto la violencia de la inscripción en el territorio que materializa la dinámica colonial. Según Vega, esta escena concretiza la "reunión más acabada de las armas y las letras". Así, se "puede concebir [la] escritura como un acto personal de servicio a la patria" en el marco de una épica patriota que apunta al "ennoblecimiento de las armas" (135).

26. La inscripción de la datación cristiana en el espacio colonial, en monumentos erigidos para rememorar el acto colonizado, produce "fetiches" que materializan y sacralizan, para los colonizados, la presencia del colón en el espacio, ver los padrões en Angola, Pietz 17.

27. Nicolopulos resalta un "drastic shift in approach" desde la primera a la segunda parte (14). Han sido abundantemente comentados el "incumplimiento de la programación épica" (Lagos) y la despedida del programático incipit "No las damas..." (AR 79). 
do se puede decir que estaba junto

todo lo natural y artificioso. [...]

No produce natura tantas flores

cuando más rica primavera envía

ni tantas variedades de colores

como en aquel jardín vicioso había. (AR 734)

Como el falso paraíso del encuentro con Carmesina, también este muro encierra un bortus conclusus, en el que la materia literaria se materializa ("historias entalladas") y las piedras preciosas condensan el deseo ("vicioso") del protagonista. Es sintomático que el precioso jardín no tiene fundación geográfica exacta. Frente a la inscripción directa y abiertamente sometedora del paisaje, aquí se huye del entorno real de la guerra de $\operatorname{Arauco}^{28}$ para refugiarse en un entorno híperreal, donde se excede lo natural y se junta "todo lo natural y artificioso" (AR 734), camuflando la violencia detrás de las superficies relucientes. Este espacio "secreto y escondido" (AR 733) y accesible solo a través de la ayuda del mago reaparece flexiblemente en uno u otro lugar, ${ }^{29}$ es completamente desterritorializado del entorno americano y aparentemente apartado del relato colonial.

A lo que Rolena Adorno describe, en este contexto, como un procedimiento texual que "dissolved into ficcion the dangerous specter of Amerindian humanity" (18) parece corresponder, al contrario, una rematerialización de la ficción. Lo que se materializa es la propia escritura -el proceso de escribir-, y la 'materia' ficcional, como objeto de deseo. En relación con el proceso de composición épica, es interesante el uso del término 'codicia'. Se ha resaltado repetidamente que la codicia de los españoles es criticada -por araucanos tanto como por el propio narrador- como una desviación del principio de bellum iustum defendido para la colonización. ${ }^{30}$ En cambio, en torno a los episodios del mago Fitón, en los cuales la propia escritura domina cada vez más la narración, el enfoque del término "codicia" adquiere un valor metapoético. De hecho, su utilización oscila entre la acumulación de prendas ("golosa presa codiciosa / [...] sacando [...] / cofres, tapices, camas y rimeros / [...] sin dejar una

28. La noción de fuga es explícita: "el entendimiento y la pluma mía / [...] huye del gran estrago que este día / hubo en los defensores de su tierra" (AR 721).

29. "[El jardín] también desta banda tiene puerta / pero a todos oculta y encubierta", AR 733.

30. Así, el texto de Ercilla no desacreditaría la idea colonial o imperial en sí, sino únicamente sus

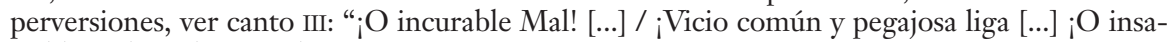
ciable codicia de mortales!" (AR 137). 
mínima ganancia”, AR 525-26), y el afán de ver y contar ("codiciosos ojos", "gran codicia de informarme", AR 542; "yo, codicioso de saber", AR 662). La 'materia' narrable llega a ser equivalente al "metal goloso" que los colones "embebecidos" sacan de las tierras americanas (AR 136). La codicia corresponde pues también a un deseo insaciable de componer texto y revelar todo mediante la escritura: ${ }^{31}$

Allí se verán hechos señalados, difíciles empresas peligrosas, [...] crudas heridas, muertes lastimosas, casos grandes, sucesos infinitos dignos de ser para en eterno escritos. (AR 533)

El excesivo afán del coleccionista que se embriaga de la propia noción de acumulación muestra también su lado problemático. ${ }^{32}$ En cambio, es significativo que la descripción de la guerra de Arauco, el suceso colonial que Ercilla se había propuesto examinar, no se muestra suficiente a esta ansia de escritura total. América, a pesar de prometer una decisiva expansión de sucesos y territorios, no ofrece al autor-protagonista "materia y campo asaz bastante" (AR 539): en vez de un "campo próspero" donde "la pluma corr[iera] / con fértil vena" (AR 519) 33 o donde "correr sin límite pudiera" (AR 564), se encuentra con un suelo árido y estéril. ${ }^{34}$ Como un "oficio / desnudo de ornamento y artificio" (AR 610), la épica colonial se ve en flagrante contraste con la ficción del magnífico muro y de la sala exuberante de Fitón. Por su parte, este mundo fantasmagórico es el resultado de la negación programática de la riqueza material del nuevo continente, del hecho de callar la procedencia del material (tanto del oro de las minas ${ }^{35}$ como de la materia épica que daba origen a la campaña épica de La araucana).

31. Como fantasía de la visión panóptica que saca lo cubierto a la luz y se lo somete, la escritura viene a ser un equivalente de la búsqueda del oro, ver canto XXVII, especialmente AR 756.

32. En el Prólogo del Bernardo es muy similar, hasta en las expresiones, la acumulación de sucesos que despiertan los sentimientos del lector: "Hice lo posible porque este poema [...] fuese una apurada tragedia, y que así lo principal de su deleite le naciese de la compasion de tantas muertes lastimosas, sucesos trágicos, destrozos de gentes, truecos de reinos" (XIX-XX).

33. La connotación vital da un contraste interesante con la isotopía de la muerte presente en la materia colonial (ver supra, las "crudas heridas, muertes lastimosas", etc.).

34. Ver AR 564: "la seca materia desgustada / tan desierta y estéril que he tomado / me promete hasta el fin trabajo sumo / y es malo se sacar de un terrón zumo".

35. En cambio, en AR 751 se revela explícitamente el comercio colonial como origen de las construcciones opulentas. También se insiste en la abundancia y el "valor subido" de las maderas y minas (AR 753-55). 
Como transmutación del material "goloso", el mundo de la imitación discursiva (de la tradición épica europea y de la poesía petrarquista, por ejemplo) disimula y re-materializa, al mismo tiempo, la materia de la conquista. No es casualidad si don Alonso halla en este entorno de la simulación y del paroxismo material, completamente disuelto del contexto de la 'realidad' americana, el máximo fetiche de sus deseos: la bola del mago Fitón. Este aparato mágico, hecho "de tal labor y costosa / que no sé lengua que contarlo pueda" y expuesto en una sala ricamente ornada de "innumerables piedras relucientes" (AR 649), condensa la experiencia del exceso de escritura (ver Friedlein 304-05) en un objeto fetiche que suscita el deseo del autor-protagonista y le simula una 'materia' ficcional plena. Reaparece aquí la codicia, centrada ahora en la adoración visual del fetiche:

Después de haber un rato satisfecho

la codiciosa vista en las pinturas

mirando de los muros, suelo y techo

la gran riqueza y varias esculturas,

el mago me llevó al globo. (AR 650)

Como el Grial, este fetiche es de nuevo una figura hueca que finge contenerlo todo: como un "redondo espejo revelado", el globo es mero espacio de proyección. Su materialidad es incierta, oscila entre el estatus de artefacto total ("de dificilísima hechura [que] / cuarenta años ha costado", AR 650) y de objeto-sujeto que acciona y vale por sí solo: "por arte y labor maravillosa / en el aire por sí se sostenía” (AR 650). El globo abre la visión al mundo del simulacro: lo que se pretende visualizar "bien manifiesto" (AR 654), no puede ser más que una ilusión, en el modo virtual del 'como si fuera' ("el mundo me mostró, como si fuera / en su forma real y verdadera", AR 735). De hecho, en este fetiche se materializa el espectro de la escritura colonial. El deseo y la codicia del material extraído de la tierra se desvían hacia el terreno de la ficción, en la cual se condensan en forma de un mundo simulado y desterritorializado.

\section{CODICIA VERSUS PÉRDIDA: LA “MATERIA MALDITA” DE LA ÉPICA COLONIAL}

Si el universo de Fitón corresponde a un mundo encubierto, lo que el texto esconde en estos capítulos, es la otra cara de la escritura encomiástica: su lado violento. El exceso de materia épica exige cada vez más víctimas. En este sentido, la "codiciosa vista" extendida desde América hacia Lepanto no es solo 
una vuelta apologética para el imperio, ${ }^{36}$ sino corresponde también a una ampliación del "campo de batalla" para la escritura. Y este exceso de escritura tiene su contrapartida en los episodios araucanos.

Aunque parezca muy heterogénea a primera vista, la segunda parte de $L a$ araucana enlaza perfectamente los episodios metapoéticos con los episodios alrededor de las pérdidas araucanas. ${ }^{37} \mathrm{Si}$ la huida al mundo híperreal de Fitón corresponde estructuralmente a las escenas de sacrificio colectivo de los araucanos, ${ }^{38}$ la textura épica revela el fondo problemático sobre el cual se funda la escritura apologética. El locus amoenus del "campo fértil” para la escritura se vuelve transparente para los cadáveres que lo nutren: los cuerpos despedazados de los araucanos. Si en los episodios de Fitón se exalta la descripción de las "crudas heridas, muertes lastimosas" (AR 533) para celebrar el canto épico ("yo, que alegrísimo miraba / todo lo que en mi canto habéis oído", AR 528), esta escritura excesiva se transforma cada vez más en una apología de la pérdida. La acumulación de la materia épica lleva consigo, en contrapartida, una pérdida de los recursos humanos: equivale pues a los "casos grandes, sucesos infinitos" esta otra visión de "muertes estrañas, golpes y heridas / de poderosos y gallardos brazos; / cabezas hasta el cuello y más hendidas, / y cuerpos divididos en pedazos" (AR 521).

Según Georges Bataille, a la lógica de la acumulación y de la ganancia se opone otro modelo económico alternativo, el "principe de la perte" (I, 305) conocido desde los primitivos pueblos y en coherencia con el funcionamiento de la propia naturaleza: el sol da sin contrapartida. Parece que a los araucanos, pueblo indómito y 'natural', les corresponde también este modo económico 'precivilizado' pero 'glorioso' en palabras de Bataille: la lógica del “don sans contredon" ${ }^{39}$ y del gasto incondicional, que no apunta al provecho sino a la pérdida, y se encuentra, en esta medida, "aux antipodes des pratiques commerciales actuelles" (VII, 69):

[I]l est nécessaire de réserver le nom de dépense à ces formes improductives, à l'exclusion de tous les modes de consommation qui servent de moyen terme à la production. [...]

36. Para la extensión de la violencia en las batallas europeas, ver Galperin.

37. Friedlein ve la heterogeneidad del texto como "sinnstiftende Autodekonstruktion" (283).

38. Ver el entrelazamiento del sacrificio de Galbarino con la visión de la cueva de Fitón (cap. XXIII), o de la derrota de los araucanos con la descripción del jardín de Fitón (cap. XXVI: "En este canto se trata el fin de la batalla y retirada de los araucanos; la obstinación y pertinencia de Galbarino y su muerte. Asimismo se pinta el jardín y estancia del mago Fitón” (AR 719).

39. Bataille se refiere a las observaciones etnológicas de Marcel Mauss, "Essai sur le don" (VII, 71). 
[L]'accent est placé sur la perte qui doit être la plus grande possible pour que l'activité prenne son véritable sens. (I, 305)

Es significativo que Bataille funde su teoría del gasto y del don en el ámbito del contacto colonial, precisamente en el México azteca observado por el misionero fray Bernardino de Sahagún (VII, 52-69). La noción de sacrificio que se celebra también por parte de los araucanos se opone a la codicia de los españoles y a su lógica de la acumulación material. Si el exceso de la escritura del autor-protagonista se ancla en la lógica de la acumulación y del querer poseer, el sacrificio de los araucanos corresponde, con Bataille, al gasto suntuoso ("dépense somptuaire”, VII, 200) de este exceso de materia, y sugiere un trato alternativo de las riquezas materiales.

Observemos más de cerca el episodio de Tegualda (AR 573-88), que se inserta en un lugar significativo del discurso: entre las visiones de las grandes batallas gloriosas en Europa y las más graves pérdidas de los soldados araucanos. Este episodio ha sido considerado como un paréntesis novelesco en el cual se proyectan la ética medieval y los valores caballerescos, ya entrados en decadencia en la España imperial del 1500, hacia el mundo indígena (Rössner 202). En cambio, a partir de los tópicos de cortesía caballeresca, el episodio parece sobre todo modelar una economía alternativa: el don de la materia, un gasto material que luego viene a ampliarse al don de sí. La hermosa indígena Tegualda le cuenta al autor-protagonista de unas fiestas cortesanas en las que había conocido a su futuro marido. En un torneo que reunía a los mejores caballeros, la dama debía entregar al vencedor como valioso premio "un anillo de esmaltes rodeado / y una gruesa esmeralda bien labrada" (AR 583). Pero en vez de querer guardar el objeto para sí, la donatriz y el ganador de la competición se devuelven mutuamente la joya, superando el don del otro y dándose, en último término, a sí mismos. En todo el relato de Tegualda son numerosas las variantes del "dar" y "ofrecer". Cuenta Tegualda:

que le diese el anillo me rogaron.

Yo, un medroso temblor disimulando [...],

del empacho y temor pasado el punto,

le di mi libertad y anillo junto.

Él me dijo: -Señora, te suplico

le recibas de mí, que aunque parece

pobre y pequeño el don, te certifico

que es grande la afición con que se ofrece; 
que con este favor quedaré rico

y así el ánimo y fuerzas me engrandece,

que no habrá empresa grande ni habrá cosa

que ya me pueda ser dificultosa. (AR 583-84)

Si la noción del don implica ofrecer al mismo tiempo su vida ("me ofrezco de vivir y morir en tu servicio", AR 580), se idealiza el amor cortesano, pero también se ilustra una pérdida incondicional que exalta el gasto total de sí y culmina así en la idea de sacrificio. ${ }^{40}$ En la sociedad araucana, el objeto precioso cuenta como lo que, según Bataille, naturalmente es: una materia 'maldita' destinada a la pérdida suntuosa. En "La notion de dépense", Bataille equipara las joyas de valor ostentatorio con los excrementos corporales, destinados a expenderse sin provecho: "[L]es bijoux comme les excréments sont des matières maudites qui coulent d'une blessure, des parties de soi-même destinées à un sacrifice ostensible" (I, 305). Como excreción de una herida, las joyas ya de por sí remiten a una violencia fundamental. Efectivamente, la historia de Tegualda funciona solo ante el horizonte de la muerte, puesto que su relato se inserta en la escena nocturna donde Tegualda busca el cadáver de su amado, y reclama para sí "la muerte y sacrificio / por último remedio y beneficio" (AR 587).

Refiriéndose a las sociedades precoloniales, Bataille indica que esta ruina total dirigida hacia la muerte conlleva una gloria que el intercambio económico interesado no puede alcanzar: "Un objet d'échange, dans ces pratiques, n'était pas une chose, il n'était pas réduit à l'inertie, à l'absence de vie du monde profane. Le don qu'on en faisait était un signe de gloire, et l'objet luimême avait le rayonnement de la gloire" (VII, 68)..$^{41}$

Así, se enaltece el sacrificio de la muerte y de los cuerpos despedazados en una fiesta casi sagrada..$^{42}$ Los cuerpos mutilados de Galbarino y Caupolicán vienen a ser el "locus de inscripción de sentido" colonial (Restrepo 248). A primera vista, la exposición de las manos cortadas de Galbarino o del cuerpo empalado de Caupolicán exalta la violencia y la dominación colonial. Pero, del

40. Para la noción de sacrificio, recurrente en Bataille, ver II, 242. Para el parentesco del potlatch con la noción de sacrificio, también VII, 70 y I, 309.

41. Ver también Bataille VII, 74: "La gloire [...] exprime un mouvement de frénésie insensée, de dépense d'énergie sans mesure, que suppose l'ardeur au combat. Le combat est glorieux en ce qu'il est toujours au-delà du calcul à quelque moment".

42. Según Bataille, "le sacrifice n'est autre, au sens étymologique du mot, que la production de choses sacrées" (I, 306). 
otro lado, con la dimensión cristológica de las figuras araucanas ${ }^{43}$ se rescriben, al mismo tiempo, las 'verdades' coloniales: Frente al cristianismo, se erigen Cristos alternativos ${ }^{44}$ que testimonian con su propia carne el "fingimiento" y las "vanas apariencias" (AR 631) de los motivos de los colonizadores: de la boca de Galbarino, el "oro goloso" aparece como verdadera causa de la conquista (AR 631), mientras que los araucanos dan prueba con sus propios cuerpos de la pérdida suntuosa de la 'materia maldita'. Y con este sacrificio inscriben en sus cuerpos una revuelta sin palabras: Con el 'don' se retiran del control de la codicia de los colonizadores y expresan su radical otredad: "la destruction est le meilleur moyen de nier un rapport utilitaire [...]", escribe Bataille (I, 61). En la lógica poética de La Araucana, el "otro" corresponde, pues, a la "materia maldita" que se tiene que dilapidar, quizás con el fin de garantizarle al relato este "rayonnement de gloire" que bajo el signo de la codicia no se concibe. $^{45}$

\section{ESCRITURA Y VIOLENCIA COLONIAL}

Me parece que estos pasajes cuestionan la escritura en sí, y la descalifican como simulacro. El gasto o el "mouvement de gaspillage euphorique" (Bataille VII, 203) que confluye con el extáctico "don de soi” (VII, 239) de los araucanos se distingue de la materialidad ostentosa de los episodios metaficcionales en cuanto al rol de la propia escritura. Es significativo que el modo alternativo del don araucano se sitúe en el ámbito de la oralidad, lejos de la simulación pervertida de la Escritura que aparece en los episodios metaficcionales alrededor de Fitón. El episodio referido es trasmitido oralmente del personaje Tegualda al narrador. A la hora de equiparar las "materias malditas" (las

43. En el sacrificio de Galbarino, la noción del "don" se retoma programáticamente (AR 623-24), encarnándola en el cuerpo fragmentado del sacrificado. La dimensión cristológica se despliega en un ecce homo que remite a la eucaristía: "Mirad aquí mi cuerpo despedazado" (AR 639); ver también Davis 47-50. En cambio, como el pueblo judío en los evangelios, también los araucanos negocian el cuerpo de su mesías contra "promesas y dádivas" y colaboran con los colonos traicionando a los suyos, ver Davis 51 .

44. Se despliega un auténtico juego de atribuciones y negaciones del paradigma cristiano entre los araucanos y los colonos. Al mismo tiempo que los araucanos se trazan como Cristos alternativos, a los españoles se les quita la legitimidad cristiana, también por parte de la voz del narrador: "los nuestros, hasta allí cristianos", AR 719). En cambio, en otro momento el narrador también trata a Galbarino como "bárbaro infernal" (AR 625), adscribiéndole al mismo tiempo rasgos diabólicos y salvajes.

45. Según Bataille, la dilapidación del potlatch conlleva el "prestige acquis par celui qui gaspille" (VII, 75). 
materias preciosas y los cuerpos humanos) en una sola 'pérdida suntuosa', el texto rehumaniza y re-territorializa, quizás a pesar suyo, la 'materia' americana, escondida precisamente en los episodios donde la escritura se hace tangible. Así, la escritura misma revela ser un mecanismo de violencia disimulada, y parece como tal estrechamente vinculada al dominio conquistador. Como indica Michel de Certeau, el "projet scripturaire", como práctica decididamente moderna, corresponde a una "pratique structurante" que impone su visión y ocupa una función estratégica: "apprendre à écrire définit l'initiation par excellence à une société capitaliste et conquérante” (200-01).

Si el don araucano está vinculado a la voz directa y a la corporalidad dirigida hacia la muerte, pertenece al orden sacral y no "simulacral". Así se cuestiona cada escritura que disfraza una violencia conquistadora tras la fachada de la imitación discursiva, pero de la cual solo conserva la pura forma. ${ }^{46}$ Si las questes de griales o los modelos caballerescos se repintan en fachadas relucientes sin guardar su referencialidad y su significado inicial, proponen una huida al puro fetiche de lo poético. La supuesta permeabilidad de las referencias intertextuales entre modelos artúricos, caballerescos y épicos se cubre con superficies materiales que condensan el perverso "deseo del código" discursivo y ocultan al mismo tiempo la referencialidad colonial. Los espacios maravillosos, donde se re-materializan estas riquezas, constituyen las fachadas que simulan un mundo donde a la escritura épica y a las hazañas heroico-caballerescas les pueda al fin corresponder -al menos en el terreno de lo poético- su merecida valoración. Pero para ocultar el nexo entre este simulacro y la referencialidad del hecho colonial, estos lugares (como la caverna de Fitón) se reprimen hacia unos reclusorios encubiertos. Estos refugios de la 'materia maldita' despliegan así toda la dimensión fantasmagórica de la atracción perversa de estas joyas-excrementos "qui coulent d'une blessure" (Bataille I, 305).

Volvemos, para terminar, a Tirant lo Blanc y a un episodio curioso, donde un filósofo llamado a la corte imperial examina una joya. Como Fitón, este es un profeta ${ }^{47}$ y le tienen mucho interés en la corte de Constantinopla -también un interés material, ya que con sus capacidades de vidente puede averi-

46. Para la noción de Verdrängung en la serie de imágenes generadas sin recurso a una referencialidad, ver Klettke 29.

47. Aunque es más bien un profeta picaresco que se desacredita desde el principio con la matanza carnavalesca en la cocina del albergue (ТВ, I 201). Ver también Penzkofer 100. 
guar el valor escondido de las cosas-. Un vendedor del norte de África viene a la corte para vender joyas, y el emperador se muestra especialmente interesado por un grueso rubí que cuesta sesenta mil ducados. Pero al examinar el rubí, le hallan pequeños huecos por un lado. El platero aconseja engastar la piedra con los agujeros por abajo para que no se le vea el fallo, pero igual se inquietan por el valor de la joya, y deciden consultar al filósofo:

Feren venir lo filòsof, e lo Rei li mostrà lo balaix. E com aquell lo véu ab los forats mès-los en lo palmell de la mà e acostàl-se prop de l'orella, tancà los ulls e estigué així per bon espai. Aprés dix:

-Senyor, en aquesta pedra ha cos viu. (TB, I 203)

$\mathrm{Al}$ romper el rubí, le encuentran, efectivamente, un gusano. La materia preciosa está, también allí, hueca. Y, como en el caso de La Araucana, esconde un cuerpo vivo: la dimensión vital y real detrás de las conquistas coloniales. El gusano podría ser signo de este memento mori que duerme en el interior del edificio colonialista, por más preciosamente que se vistan sus fachadas. Tanto el legado caballeresco orientalista como las actualizaciones de estas conquistas en la épica colonial -discursos afines en cuanto a su dimensión encomiástica y la voluntad de transferir las questes de griales poéticos hacia nuevos territoriosno pueden, pues, negar su fundación en un núcleo problemático detrás de la suntuosa materialización de su supuesto valor moral y poético.

\section{OBRAS CITADAS}

Adorno, Rolena. "Literary Production and Suppression: Reading and Writing about Amerindians in Colonial Spanish America". Dispositio 11.28/29 (1986): 1-25.

AR: Alonso de Ercilla. La Araucana. Ed. Isaías Lerner. Madrid: Cátedra, 2009. Badia, Lola. "El Tirant en la tardor medieval catalana". Actes del Symposion Tirant lo Blanc. Barcelona: Quaderns Crema, 1993. 35-100.

Balbuena, Bernardo de. El Bernardo: poema heroyco. Vol. 1. 2. ${ }^{\text {a }}$ ed. Madrid: Imprenta de Sancha, 1808.

Bataille, George. Euvres complètes. 8 vols. Paris: Gallimard, 1970-1976.

Baudrillard, Jean. Pour Une Critique de l'économie politique du signe. Paris: Gallimard, 1972.

Baudrillard, Jean. L'Échange symbolique et la mort. Paris: Gallimard, 1976.

Baudrillard, Jean. Simulacres et simulation. Paris: Galilée, 1981. 
Beltrán, Rafael. Tirant lo Blanc, de foanot Martorell. Madrid: Síntesis, 2006.

Béreiziat-Lang, Stephanie. "Espejos distorsionados: deformación anticaballeresca, usurpación de poder y subversión literaria en Tirant lo Blanc". Iberoromania 88 (2018): 115-34.

Blättler, Christine. "Fetisch, Phasmagorie und Simulakrum". Gegenwart des Fetisch: Dingkonjunktur und Fetischbegriff in der Diskussion. Eds. Christine Blättler y Falko Schmieder. Wien/Berlin: Turia + Kant, 2014. 27994.

Caravaggi, Giovanni. "Descubrimientos y conquistas en la épica: aspectos del debate teórico". La teoría de la épica en el siglo XVI. Eds. María José Vega y Lara Vilà. Vigo: Academia del Hispanismo, 2010. 205-17.

Cátedra, Pedro. "Realidad, disfraz e identidad caballeresca". Libros de caballerías (de Amadís al Quijote): poética, lectura, representación e identidad. Eds. Eva Belén Carro Carbajal, Laura Puerto Moro y María Sánchez Pérez. Salamanca: SEMYR, 2002. 71-85.

Certeau, Michel de. L'Invention du quotidien, 1: Arts de faire. Paris: Gallimard, 1990.

Davis, Elizabeth. Myth and Identity in the Epic of Imperial Spain. Columbia: UMP, 2000.

Folger, Robert. "Der episch-koloniale Fetisch: Luis Camões' Os Lusíadas". Zeitsprünge 21.3 (2017): 389-410.

Friedlein, Roger. Kosmovisionen: Inszenierungen von Wissen und Dichtung im Epos der Renaissance in Frankreich, Portugal und Spanien. Stuttgart: Steiner, 2014.

Gagliardi, Donatella. "Entre fábula, épica e historia: definiciones del género caballeresco en la España del siglo XVI". La teoría de la épica en el siglo ХVI. Eds. María José Vega y Lara Vilà. Vigo: Academia del Hispanismo, 2010. 241-67.

Galperin, Karina. "The Dido Episode in Ercilla's La Araucana and the Critique of Empire". Hispanic Review 77.1 (2009): 31-67.

Goldberg, Harriet. "Clothing in Tirant-lo-Blanc: Evidence of «Realismo vitalista» or of a New Unreality”. Hispanic Review 52.3 (1984): 379-92.

Harney, Michael. "Economy and Utopia in the Medieval Hispanic Chivalric Romance". Hispanic Review 62 (1994): 381-403.

Klettke, Cornelia. Simulakrum Schrift: Untersuchungen zu einer Ästhetik der Simulation bei Valéry, Pessoa, Borges, Klossowski, Tabucchi, Del Giudice, De Carlo. München: Fink, 2001. 
Lacan, Jacques. Séminaire VII: L'Étbique de la psychanalyse. Paris: Seuil, 1986.

Lagos, Ramona. "El incumplimiento de la programación épica en La Araucana". Cuadernos Americanos 40 (1981): 157-91.

López Pinciano, Alonso. Philosophia Antigua Poética. Vol. 3. Ed. Alfredo Carballo Picazo. Madrid: CSIC/Instituto Miguel de Cervantes, 1973.

Nicolopulos, James. The Poetics of Empire in the Indies: Prophecy and Imitation in La araucana and Os lusíadas. University Park: Pennsylvania State UP, 2000.

Pastor, Beatriz. Discursos narrativos de la conquista: mitificación y emergencia. Hanover: Ed. del Norte, 1988.

Penzkofer, Gerhard. "Die aventure des Romans: Roman und Novelle in Martorells Tirant lo Blanc". Sonderwege in die Neuzeit: Dialogizität und Intertextualität in der spanischen Literatur zwischen Mittelalter und Aufklärung. Eds. Wolf-Dieter Lange y Wolfgang Matzat. Bonn: Romanistischer Verlag, 1997. 83-104.

Pietz, William. "The Problem of Fetish I". Res: Anthropology and Aesthetics 9 (1985): 5-17.

Prampolini, Ida Rodríguez. Amadises de América: la hazaña de Indias como empresa caballeresca. 2. ${ }^{\text {a }}$ ed. Caracas: C.E.L.R.G., 1977.

Quint, David. Epic and Empire: Politics and Generic Form from Virgil to Milton. Princeton: Princeton UP, 1993.

Restrepo, Luis Fernando. "Somatografía épica colonial: las Elegías de Varones Ilustres de Indias de Juan de Castellanos". MLN 115.2 (2000): 248-67.

Rodríguez de Montalvo, Garci. Amadís de Gaula. Ed. Jesús Rodríguez Velasco. 2 vols. Madrid: Biblioteca Castro, 1997.

Rössner, Michael. “¿América como exilio para los valores caballerescos? Apuntes sobre la Numancia de Cervantes, la Araucana de Ercilla y algunos textos americanos en torno al 1600”. Estudios Aureos II: actas del XII Congreso de la AIH 1995. Vol. 3. Ed. Jules Whicker. Birmingham: Department of Hispanic Studies, 1998. 194-203.

TB: Joanot Martorell. Tirant lo Blanc. Ed. Martí de Riquer. 2 vols. Barcelona: Edicions 62, 1983.

Vargas Llosa, Mario. Carta de batalla por Tirant lo Blanc. Barcelona: Seix Barral, 1991.

Vega, María José. "Idea de la épica en la España del Quinientos”. La teoría de la épica en el siglo ХИI. Eds. María José Vega y Lara Vilà. Vigo: Academia del Hispanismo, 2010. 103-35. 
Vilà, Lara. "Fama y verdad en la épica quinientista española: el virgilianismo político y la tradición castellana del siglo XV". Studia Aurea 4 (2010): 115.

Wild, Gerhard. "«Viajes en Turquía» oder: Wie sich der Ritterroman «orientalisierte»”. Raumerfabrung - Raumerfindung: Erzäblte Welten des Mittelalters zwischen Orient und Okzident. Eds. Laetitia Rimpau y Peter Ihring. Berlin: Akademie, 2005. 235-50.

Yates, Alan. "Tirant lo Blanc: The Ambiguous Hero". Hispanic Studies in Honour of Frank Pierce. Ed. John England. Sheffield: UP, 1980. 181-98.

Žižek, Slavoj. Traverses. Paris: Centre Georges Pompidou, 1998. 